\title{
A CFD Study with Fuzzy Logic Pitch Angle Turbine Control Implementation for OWC Generation System
}

\author{
M. Madaci, D. Kerdoun \\ LGEC-Research Laboratory, Department of Electrical Engineering, Constantine 1 University, 25000 Constantine, \\ Algeria
}

\begin{tabular}{|c|c|}
\hline Article Info & ABSTRACT \\
\hline Article history: & \multirow{8}{*}{$\begin{array}{l}\text { The paper takes the improvement of the performance for an OWC converter } \\
\text { from the mechanical side. A FEM model of the OWC conversion structure } \\
\text { was proposed, studied and simulated using a CFD simulator. A novel wave } \\
\text { generation method was applied through the RWMD method (Real Wave } \\
\text { Model Simulator) instead of using an ordinary sin wave generator on the tank } \\
\text { to make the waves the closest possible to the real sea waves. A mechanical } \\
\text { prototype was built for this purpose to get an oscillated wave model. On the } \\
\text { electrical side, a pitch angle control system based on fuzzy set was applied } \\
\text { on the turbine to be auto-adapted for the fast variation of the airflow speed to } \\
\text { establish and maximize the extracted power from the OWC device. The } \\
\text { model have been studied, simulated, implemented and tested to validate the } \\
\text { obtained results. }\end{array}$} \\
\hline Received Mar 17, 2017 & \\
\hline Revised May 20, 2017 & \\
\hline Accepted May 21, 2017 & \\
\hline Keyword: & \\
\hline (OWC) Oscillating conversion & \\
\hline Chamber device & \\
\hline $\begin{array}{l}\text { CFD Computitional fluid } \\
\text { dynamics }\end{array}$ & \\
\hline
\end{tabular}

FEM Fenite element mothode

Fuzzy logic system control and implementation

Pitch Turbine control

RWMD method real wave model simulator
Copyright $@ 2017$ Institute of Advanced Engineering and Science. All rights reserved.

\section{Corresponding Author:}

Madaci Mansour,

Department of Electrical Engineering,

National Constantine University,

Road Ain Elbay, Constantine 25000, Algeria.

Email: zoldaioque@gmail.com

\section{INTRODUCTION}

Renewable energies penetration is continuously increasing through many power systems around the world. In an effort to integrate them from a part and minimize the emission of toxic gases and pollution from another part; the renewable energies are the only issue to satisfy the growing needs for energy that resulted a dependency on fossil fuels and oil. Among various natural renewable energies, wave energy is one of the most promising forms of ocean renewable sources it is the most abundantly available, applicable and largely unexploited energy in most coastal and offshore areas. During the last decade, a big interest has been given to a plenty of wave energy absorption systems and different topologies and structures were invented. In this context, several technology categories are available: overtopping devices, surging devices, oscillating water columns (OWC) [1], [2]. The Land Installed Marine Power Energy. Transmitter (LIMPET) [3], point absorbers, Offshore Floating Ocean Energy System (OFOES)[4]. The Multiple Oscillating Water Column (MOWC) [5]. Based on the (OWC), the NEREIDA demonstration project in Mutriku in Spain consisting of $16 \mathrm{~kW}$ and $18.5 \mathrm{~kW}$ turbines [6], [7]. (MOWC) Muti -resonant Oscillating Water Column Principe installed

Off the South West Coast of India near Trivandrum a $150 \mathrm{~kW}$ wave power plant prototype [8]. Land Installed Marine Power Energy Transmitter (LIMPET) on the island of Islay, west coast of Scotland [9].

On this paper, the performance of a performed OWC converter on both sides the mechanical and the electrical has been taken. The authors have made deep detailed studies on the effect of the shape and the form of the structure on the efficiency and the power quantity, by investigating the performance of individual 
components and focusing on the improvement of their characteristics to make successful OWC study and design and to be a full system analysis.

In this context an OWC test prototype of the oscillating water column converter was simulated and constructed. The tests and the results were done experimentally have confirmed the calculated ones. The variation of the airflow velocity lead to the variation of the generated power and an instable energy will be produced depends on the incident wave form, for the maximization of the energy rate form a side and improve the quality of by minimizing the fluctuations from another side, a pitch angle system have been studied and constructed, the model have been implemented and tested to validate the results.

\section{OWC-PLANTS MODELING}

The OWC (Figure 1) is a device constructed to convert the ocean incident wave from massive mechanical power to a kinetic airflow power. On another stage this latter will be converted to a mechanical power through the OWC turbine and the last step is the conversion of the mechanical power to electrical using different possible topologies by using an IG (induction generators), DFIG (doubly feed induction generators), SG (synchronous generators).

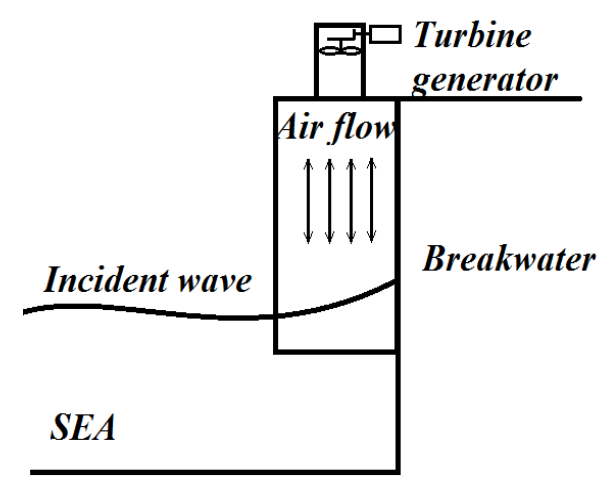

Figure 1. Outline of Oscillating Water Column (OWC) Device

\subsection{Sea Wave Model and the Wave Propagation}

The wave-energy absorption is strongly depended on the sea wave oscillations; the movement of this latter is a time varying oscillatory phenomena. In order to make an adequate wave model, it is necessary to take into account the wave form variation to get an overview on the amount of wave energy as a function of the wave frequency.

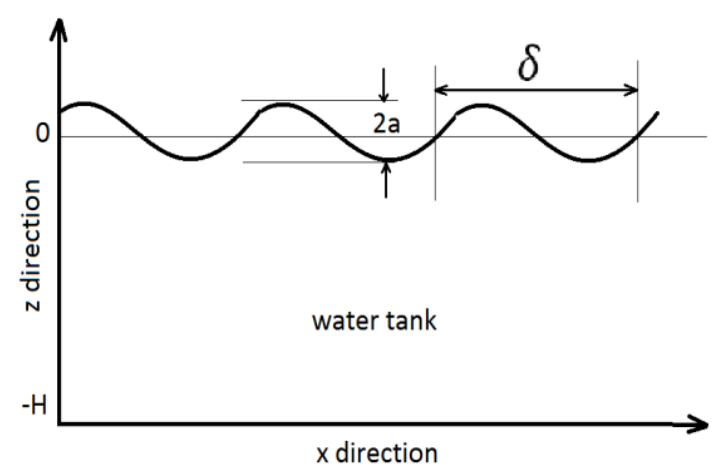

Figure 2. Incident Wave Propagation on the $(\mathrm{X}, \mathrm{Z})$ Frame

The water is considered as an incompressible fluid, with a density $\rho$. In the rest, the free surface sparing air-water on the limit is taken as an origin for the vertical axis. 
In the presence of swell the surface oscillations could be represented by the following function:

$$
h(x, t)=a \cdot \cos [j(w t-k x)]=a \operatorname{Re}\{\exp [j(w t-k x)]\}
$$

This determines contact free surface air-water where: from figure 2 and the equation (1): $a$ presents the wave amplitude, $k=2 \pi / \delta$ and $\delta$ is the wave length.

From another side, on a bidirectional frame, the velocity for a particle from the fluid on the $(x, z)$ frame as an origin for the fluid movement on the same frame since $\left(x_{0}, z_{0}\right)$ is the initial position of the particle on the time $(\mathrm{t}=0)$ and on a complex notation:

$$
\vec{v}=\left[v_{x}(h) \vec{e}_{x}+v_{z}(h) \vec{e}_{z}\right]\{\exp [j(w t-k x)]\}
$$

$v_{x}, v_{z}$ present the fluids movement velocity along the $\mathrm{x}$ and $\mathrm{z}$ direction respectively.

The pressure on this point could be given with

$$
p=p_{0}-\rho g h+p_{1}(h) \exp [j(w t-k x)]
$$

The initial conditions with the absence of swell the previous equation became:

$$
p=p_{0}-\rho g h
$$

In the case of incompressible fluid $\rho=$ Constant $\square \square$ div $\vec{v}=0$

$$
\frac{D \vec{v}}{D t}=\vec{g}-\frac{1}{\rho} \overrightarrow{g r a d} p
$$

So the particle's velocity on the $\mathrm{x}, \mathrm{z}$ directions respectively will be:

$$
\begin{aligned}
& \frac{D \overrightarrow{v_{x}}}{D t}=-\frac{1}{\rho} \frac{\partial}{\partial x}\left\{p_{1}(h) \exp [j(w t-k z)]\right\} \\
& \frac{D \overrightarrow{v_{z}}}{D t}=-\frac{1}{\rho} \frac{\partial}{\partial z}\left\{p_{1}(h) \exp [j(w t-k z)]\right\}
\end{aligned}
$$

The free surface's profile is given by

$$
h(x, t)=a \operatorname{Re}\{\exp [j(w t-k x)]\}
$$

The velocity of an elementary particle moves on the $\mathrm{z}$ direction for a given point $v_{z}(h=-H)$ which is on the deep down of the tank is equal to zero.

To avoid the complex equations the profile will be:

$$
h(x, t)=a\{\exp [j(w t-k x)]\}
$$

From another side the particle's velocity as said before $v_{z}(h=-H)=0$.

$$
\begin{aligned}
& \frac{D \overrightarrow{v_{x}}}{D t} \approx \frac{\partial \overrightarrow{v_{x}}}{\partial x}=j w v_{x}(h) \exp [j(w t-k x)] \\
& =\frac{j k}{\rho} p_{1}(h) \exp [j(w t-k z)]
\end{aligned}
$$




$$
\begin{aligned}
& v_{x}(h)=\frac{k}{\rho w} p_{1}(h) \\
& \frac{D \overrightarrow{v_{z}}}{D t} \approx \frac{\partial \overrightarrow{v_{z}}}{\partial x}=j w v_{z}(h) \exp [j(w t-k x)] \\
& =-\frac{1}{\rho} \frac{d p_{1}(h)}{d z} \exp [j(w t-k x)] \\
& v_{z}(h)=\frac{j}{\rho w} \frac{d p_{1}(h)}{d z}-j k v_{x}(h)+\frac{d v_{z}(h)}{d z}=0 \\
& \frac{d^{2} p_{1}(h)}{d z^{2}}-k^{2} p_{1}=0 \\
& p_{1}(h)=A \exp (k h)+B \exp (-k h) \\
& v_{x}=\frac{k}{\rho w}[A \exp (k h)+B \exp (-k h)] \\
& v_{z}=\frac{j k}{\rho w}[A \exp (k h)+B \exp (-k h)]
\end{aligned}
$$

The effect of the deep on the wave oscillations for the power could be by replacing

$$
v_{z}(h=-H \rightarrow-\infty)=0 \text { For this } B=0
$$

The previous equations could be written as follow to extract the position of a particle belongs to the fluid on the same frame $(\mathrm{x}, \mathrm{z})$

$$
\begin{aligned}
& p_{1}(h)=A \exp (k h) \\
& v_{x}=\frac{k}{\rho w}[A \exp (k h)] \\
& v_{z}=\frac{j k}{\rho w}[A \exp (k h)]
\end{aligned}
$$

The position on this case:

$$
\begin{aligned}
& \frac{\partial x}{\partial x}=\frac{k}{\rho w} A \exp (k h) \exp [j(w t-k x)] \\
& \frac{\partial z}{\partial x}=\frac{j k}{\rho w} A \exp (k h) \exp [j(w t-k x)]
\end{aligned}
$$

Since for the initial conditions

$$
\begin{aligned}
& h(x, t)=a \cos [j(w t-k x)] \\
& =\frac{k}{\rho w} A \exp (k h) \cos [j(w t-k x)]
\end{aligned}
$$




$$
\begin{aligned}
& h(x, t)=\frac{k}{\rho} A \cos [j(w t-k x)] \\
& k h=\frac{2 \pi}{\delta} h=\frac{2 \pi}{\delta} a \approx 0 \rightarrow A=\frac{\rho w^{2} a}{k}
\end{aligned}
$$

On the free surface sparing air-water on the limit which was taken as an original to the vertical frame:

$$
\begin{aligned}
& p_{1}=p_{0}-\rho g h+\frac{\rho w^{2} a}{k} \exp (k h) \cos (w t-k x) \\
& h(x, t)=a \cos [j(w t-k x)] \\
& =\frac{\rho w^{2} a}{k} \exp (k h) \cos (w t-k x) \\
& \text { For } \frac{w^{2}}{g k}=1 \\
& h(x, t)=\frac{w^{2} a}{g k} \cos (w t-k x)
\end{aligned}
$$

\subsection{Sea OWC Capture Chamber}

The continuity law for the an orifice device (Figure 3 ) is :

$A 1 . V 1=A 2 . V 2=Q$

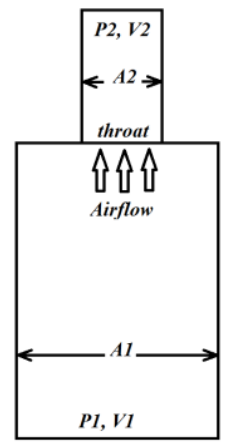

Figure 3. OWC Capture Chamber Structure.

Since $Q$ determines the quantity of fluid flowing along the tube and $V 1 . V 2$ are the fluid velocities through the areas $A 1, A 2$ respectively.

The airflow velocity is proportional to the ratio A1/A2 multiplied by the incident wave velocity through the $\mathrm{Z}$ direction.

The OWC conversion chamber is constructed of two chambers: the compression chamber for the compression of the airflow pressure to increase its velocity, and the turbine generator chamber were the electrical system is placed. The table below gives the different dimensions of the proposed prototype model. The table1 gives the dimensions for the real model prototype. The model has been modeled and constructed regarding these dimensions. A numerical modeling of the tested model on 3D frame (figure 4) and $2 \mathrm{D}$ frame (figure 5) have been done using CFD module under COMSOL ${ }^{\circledR}$ software. Looking to the unchanged obtained results between the $2 \mathrm{D}$ and $3 \mathrm{D}$ modelization, the tested model and the obtained results are almost done using the $2 \mathrm{D}$ frame to reduce the calculation time. The figure 5 gives the behavior of the structure under $12 \mathrm{~m} / \mathrm{s}$ constant air flow through both the high and the low pressure chambers. From another way, the figure 6 gives the interior pressure crossing to the inside of the structure during the upstream phase for a constant inflow of $12 \mathrm{~m} / \mathrm{s}$ speed. 
Table 1. OWC Capture Chamber Structure Dimensions

\begin{tabular}{ccc}
\hline & Turbine generator chamber & Compression chamber \\
\hline HEIGHT $(\mathrm{cm})$ & 40 & 100 \\
LARGER $(\mathrm{cm})$ & 20 & 40 \\
\hline
\end{tabular}

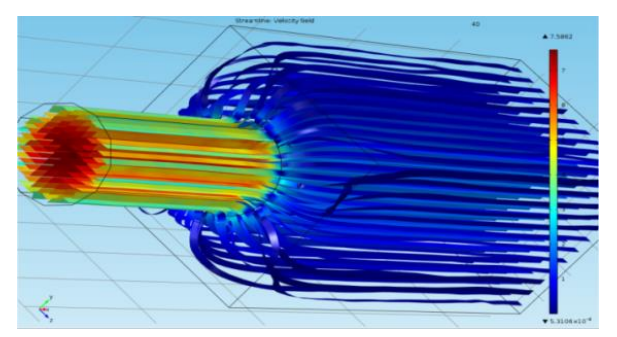

Figure 4. The Airflow Streamline for the Flow Along the OWC Capture Chamber for a Constant Flow Velocity

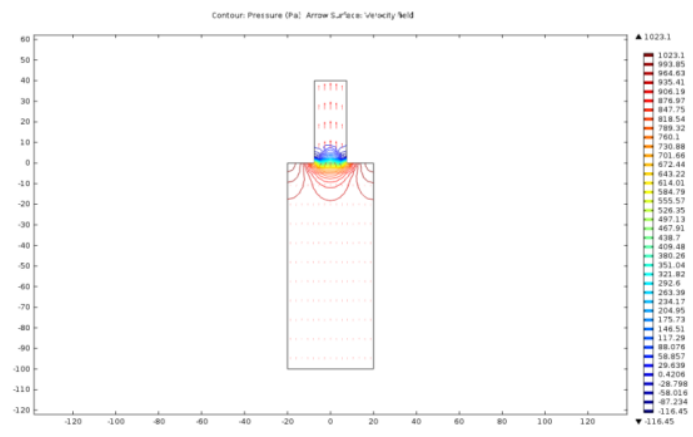

Figure 6. OWC Capture Chamber Pressure Available in the Compression Chamber

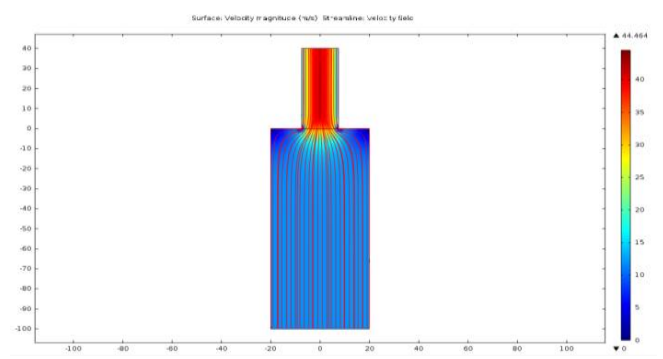

Figure 5. OWC Capture Chamber Structure Modeling in FEM

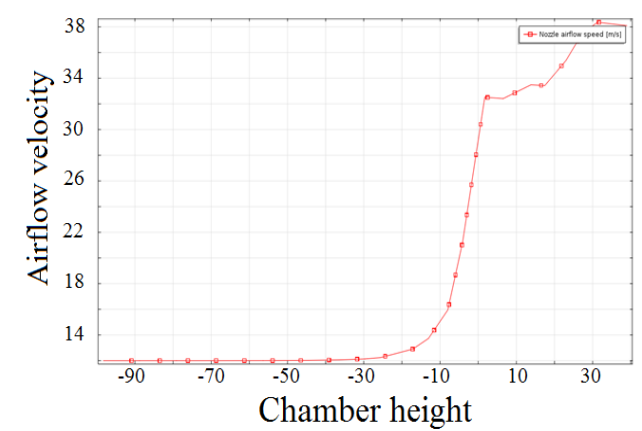

Figure 7. The Airflow Velocity Along the OWC Capture Chamber for a Constant Flow Velocity From the Inlet $(12 \mathrm{~m} / \mathrm{s})$.

The graph above (figure7) gives the airflow velocity variation along the OWC capture chamber structure for a constant applied air from the inlet of the sculpture, the airflow velocity through $2 / 3$ of the chamber still the same as the inlet velocity. For the rest of the compression chamber height the flow takes a high velocity value due to the compression on that area where the throat takes a small area. This data has been used later for the control of the turbine pitch angle a concentrator device for the chamber.

\section{OWC TURBINE MODELING AND CONTROL}

The different levels on the conversion train need to be analyzed to improve the overall system efficiency. For this goal, each part from the OWC system has been taken individually; the incident wave form, the compression chamber with its performances, and the turbine model.

The energy extraction on the OWC system is done during two phases: downstream and upstream; during the first phase, the incident wave rises on the compression chamber producing a high pressure on the collector, the airflow takes on the first direction. The moment when the elevation surface falls down, this makes a lower pressure on the compression chamber than the atmospheric pressure; this drugs the ambient air to come inside the chamber on the next direction. The generator on this case has to keep its original direction looking the high inertia of the mechanical system. Two large kinds of turbines are mostly used for the OWC energy conversion: The Wells Turbine and The impulse Turbines. The structure of these turbines allows the turbine to take one direction against the variations of the airflow on the duct of the OWC chamber but this does not improve the extraction ratio of the energy from the incident wave. Defining the characteristics of the turbine is necessary in order to clarify the effect of the oscillating flow on this latter. This is possible by solving the mechanical identification equations by using one of the numerical analytical implicit and explicit iterative methods. 


\subsection{Incident Wave Form and the RWMD Method}

To study the behavior of the system including both the structure and the turbine, the incident wave form is so important and the more the model is close to reality the more the system is reliable.

The majority of the studies and the published works take the incident wave on their studies as a sinusoidal wave form or the ISSC (International Ship Structure Congress) spectrum, for reasons to give the model less complexity during the calculation process. However, since the wave form is an irregular wave containing variable parameters which are NOT periodically vary; this affects the obtained results and affects the behavior of the studied model.

RWMD method (Real Wave Model Simulator is the issue that has been used by the authors to get a close model to the real wave form instead of using an ordinary sin wave generator. The method based initially on the generation of irregular waves on a tank through a mechanical device illustrated on the figures 8(a) and (b), an ultrasonic sensor has been used to get the state of the elevation surface, then the data has been stored on a table as an array, the regenerated wave was fitted and implemented on the TMS320C7611 board based on $150 \mathrm{MHz}$ clock to be used as a reference for OWC system.

The figure 9 given bellow illustrates the fitted curve of the captured data for the constructed prototype.

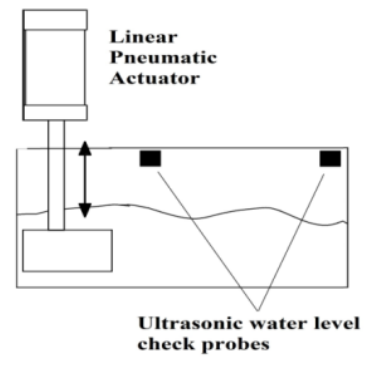

(a)

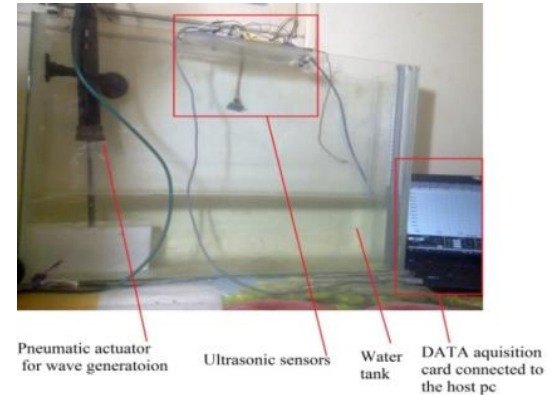

(b)

Figure 8. The Built Prototype for Wave Form Extraction Model

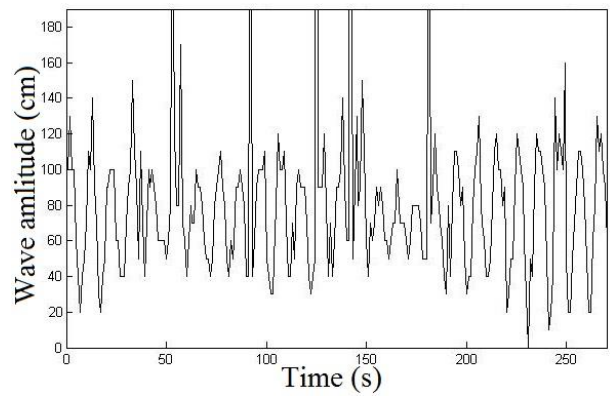

Figure 9. Fitted Curve of the Lookup Table From the Captured Data on the Oscillated Water Prototype

\subsection{Estimation of Turbine Performances and Characteristics}

The mainly objective of the current work is to investigate the performances of an OWC chamber by the improvement of its different parts.

$$
\begin{gathered}
C_{A}=\frac{\Delta p}{\rho_{a} \omega^{2} R_{t}^{2}} \\
C_{T}=\frac{T}{\rho_{a} \omega^{2} R_{t}^{5}}
\end{gathered}
$$




$$
Q=v_{\omega} / u_{\omega}=\left(Q_{\omega} / A_{\omega}\right) /\left(R_{t} / \omega\right)
$$

$$
\eta=\frac{T \omega}{\Delta p Q}
$$

$\Delta \mathrm{p}$ is the differential pressure crossing the turbine section, whereas $\rho \mathrm{a}$ is the atmospheric air density, $\mathrm{Q}$ is the volume flow rate across the chamber area and $\mathrm{Q} \omega$ is the volume flow rate across the turbine area initially $\mathrm{Q} \omega=\mathrm{Q}$ this gives less complication during the calculation process, $\mathrm{T}$ denotes the turbine torque characteristics.

The flow rate coefficient with is the ratio of the axial air velocity $v \omega$ by the turbine tip speed $\omega \mathrm{Rt}$ could be determined as follow:

$$
\phi=\frac{Q}{\omega R_{t}^{3} \pi}=\frac{v}{\omega R_{t}}
$$

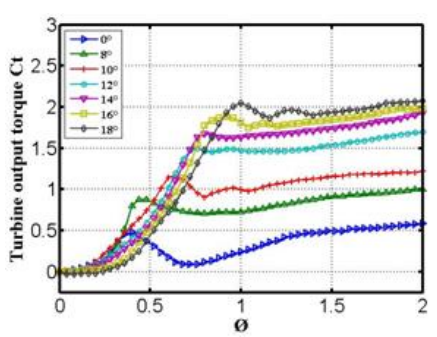

(a)

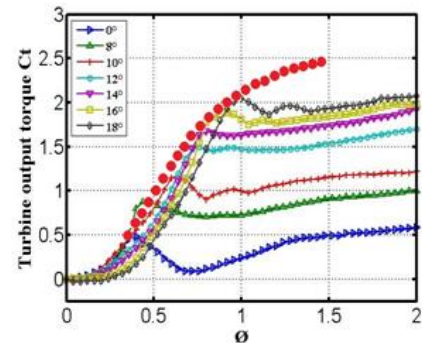

(b)

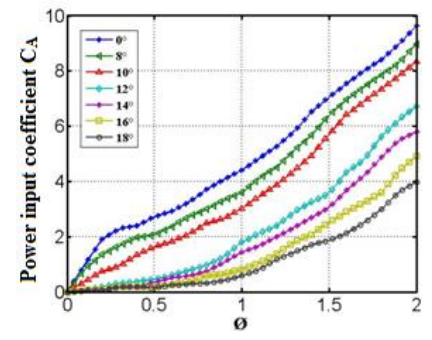

(c)

Figure 10. OWC Capture Chamber Pressure Available in the Compression Chamber

The characteristics CT- $\phi$ for different pitch fixed angles have been illustrated on the Figure 10(a). the figure shows that the behavior of the turbine for a steady state flow it gives a negative torque this makes the turbine similar to a fan for low flow rates. The figure shows even that for each fixed pitch angle the turbine gives a peak of maximum torque CT. From the obtained results, we can say that the turbine gives a maximum expenential variable torque-figure 10(b)-with inceasing of the flow rate through this later.

We can say that the turbine could keep its output torque at the maximum through the control of the pitch angle for the different range of the flow rate.

On another side, the Figure 10(c) shows that the input power coefficient CA is increasing with the decrease of the pitch angle values which is evident since the pressure in the air chamber decrease with the increase of the pitch angle.

\subsection{Turbine Pitch Angle Control Topology}

The main aim of this work is to maximize the extracted power from the OWC and to improve the energy quality for such devices; a fuzzy logic control system based on triangle membership function is proposed to handle this duty. This allows a fast implementation and gives a quick process to the system; the centroid method is used for defuzzification stage.

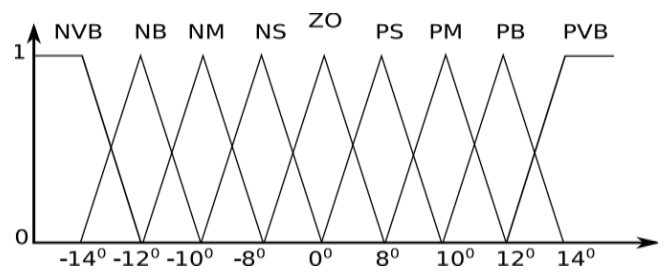

Figure 11. The Nine Membership Functions of Inputs and Outputs 
The Figure 11 shows the nine membership functions used for the control topology, nine fuzzy sets have been considered for the input which is the wind speed: negative very big (NVB), negative big (NB), negative medium(NM), negative small (NS), zero(ZO), positive very big (PVB), positive big (PB), positive medium(PM), positive small(PS).

\subsection{Experimental System Setup and Implementation}

For the pitch angle control system Figure 12, a DC motor based on angle position control model was used. For this purpose, the regulation of the mechanical system was achieved by a simple PI regulator that drives the actuator to follow the reference. The control angle reference is the output of a fuzzy logic system that controls the angle pitch along the different airflow velocity variations produced by the incident wave.

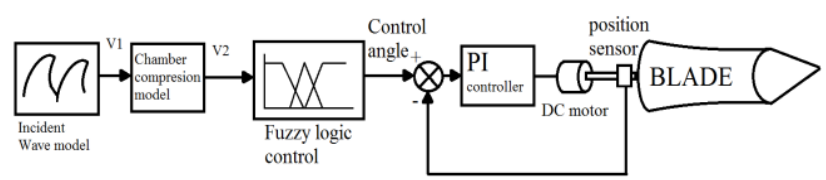

Figure 12. Pitch Angle Block Control System

The fuzzy logic controller and the pitch angle actuator control were implemented on a TMS32F407 board control with an ARM controller based on $168 \mathrm{MHz}$ clock as illustrated on figure 13(a). Since the output of the board on the lineout port is only a positive value even for the ADC port for the DSP STM320 figure 13(b), the data was shifted to take positive values; negative ones were created compared with a reference to give the ability to the system to control the angle during the phases of the production.

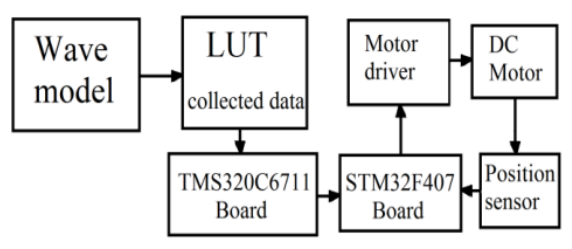

(a)

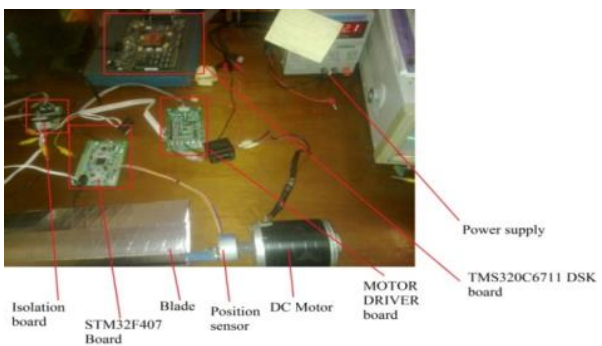

(b)

Figure 13. (a) Block Diagram for the Pitch Angle Control System. (b) The Experimental Built Control Model for Pitch Control

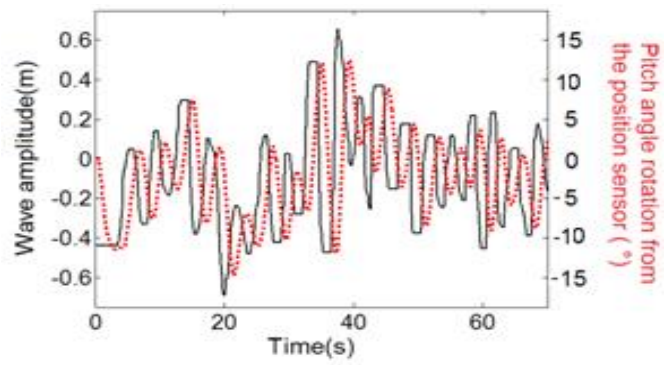

Figure 14. Pitch Angle Behavior for the Incident Oscillated Wave

The behavior of the pitch angle control system to the applied changes (Figure 14) demonstrates that the system used can handle the duty. The minimization of the perturbations for the captured power allows the maximization of that latter and gives a smooth power on the output this from a side. From another, the 
control of the extracted power during the two phases of the wave movement and the period of transaction avoid the propagation of the power fluctuation to the grid in the case of the directed linked system.

\section{CONCLUSIONS}

The paper gives the present status of the art on air turbines for wave energy conversion. The characteristics of air turbines for wave energy conversion proposed so far were investigated by numerical simulation and sea trial under irregular flow conditions. A proposed model for the OWC wave form has been proposed and experimentally validated. The authors give in this paper the main topology process for the control of pitch angle controlled Wells turbine, this idea has been simulated and experimentally implemented and tested. Using a controlled pitch angle in the range of $30^{\circ}>\alpha>6^{\circ}$ insure for the system a high production and smooth quality production. The boundaries angles $6^{\circ}$ and $30^{\circ}$ are the angle parameters limits for the system control, out of this range it found that the OWC conversion chamber lost its compression characteristics for the proposed turbine model

\section{ACKNOWLEDGEMENTS}

This material is based on work supported by the LGEC (laboratoire de génie élèctrique) laboratories, faculty of ELECTRICAL ENGINEERING. Constantine 1 University within the fund for research groups of electrical laboratories of the UNIVERSITY OF CONSTANTINE1 within the current research topic EnR 2015-2030 supported by the Ministry of Mines and Energy (MME) of Algeria.

\section{REFERENCES}

[1] K. Y. Hong, S. H. Shin, D. C. Hong, H. S. Choi and S. W. Hong. Effectsof shape parameters of OWC chamber in wave energy absorption. Proc 17th Int Offshore and Polar EngConf, Lisbon, Portugal, ISOPE, 2007.Vol. 1, pp. 428-433.

[2] Y. G. You, Hydrodynamic analysis on wave power devices in nearshorezones. Journal of Hydrodynamics, Ser. B 1993. Vol. 5, pp. 42-54.

[3] Heath T, Whittaker T, Boake C. B. "The design, construction and operation of the LIMPET wave energy converter (Islay Scotland)". In: The fourth European Wind Energy Conference. Aalborg, Denmark. 2000, pp.78 83.

[4] N.A. Brown and D.A. Innis, (2013); “Offshore Floating Ocean Energy System," US Patent No.8,446,030 B2

[5] Johnson F, Chudley J, Dai Y. M. "Prolongation of the Deployment and Monitoring of a Multiple Oscillating Water Column Wave Energy Converter".The University of Plymouth, UK.2003, pp.23 32.

[6] Basque Energy Board (EVE). [Online]. Available: http://www.eve.es/web/Energias-Renovables/Energiamarina.aspx?lang=en-GB.

[7] Y.Torre-Enciso"Mutriku Wave Power Plant: From conception to reality,"Eur.Fed. Of Region.Energy and Environ. Agencies (FEDARENE), Brussels, Belgium, Dec.2009.

[8] M. Delucchi, "Wind, water and solar power for the world," IEEE Spectrum Online, Sep. 2011.

[9] AlconR. G; BeattieW. C." Observations of time domain dataon the Wells turbine in the islay wave power plant", .In: Proceedings of the eighth Internaional Offshore and polar Engineering Conferences.Montrial, Canada: International Society of Offshore and Polar Engineers, 1988. pp.12 18. 